\title{
EDitorial
}

\section{COMU Scientific Awards}

Dear readers,

In 2019, we celebrate the 38th edition of our University Medical Congress (COMU), organized by the Scientific Department of the Faculty of Medicine of the University of São Paulo (DC FMUSP). It is the largest scientific meeting in Brazil for health students.

This year, COMU has been expanded to accommodate over 60 courses and workshops, covering issues that called the attention of students from all areas of health sciences and from all undergraduate periods. In addition, the Congress has been designed in a modular way, so that each student can create the program that best suits their knowledge and interests. In addition to the theoretical and practical courses, COMU also offers the opportunity for students to present their research and compete for the Scientific Awards.

We have received scientific papers from students from all over Brazil, and in order to encourage internationalization and exchange, since 2016 candidates for these awards send their written papers written and presented in English. FMUSP professors of high scientific knowledge evaluate the works in their specific areas of competence.

Therefore, we have a Congress capable of providing a unique and complete academic experience. Students not only receive useful information for their future professional practice, but also have the opportunity to innovate and develop scientific thinking, skills that in the near future will be more than a routine, a real necessity.

In this issue, we cover all the abstracts presented orally at the Scientific Awards. Our journal of the Scientific Department, Journal of Medicine, is an essential part of this context, publishing for over a century the highest quality articles that address issues of utmost importance to the scientific community.

Finally, we thank all of the Scientific Department and the Revista de Medicina for their help and support, always essential to our Congress, and congratulate the academic authors of the publication for their dedication to research and science.

\author{
Heraldo Possolo de Souza \\ Professor at FMUSP \\ Honorary President of the Scientific Awards
}

\section{Mateus Barradas Ribeiro}

Academic of FMUSP

President of the Scientific Department

President of the Scientific Awards 